\title{
Strain Rockbursts Simulated by Low-Strength Brittle Equivalent Materials
}

\author{
Lang Li, ${ }^{1,2}$ Mingyang Wang, ${ }^{1}$ Pengxian Fan, ${ }^{1,2}$ Haiming Jiang, ${ }^{1}$ Yihao Cheng, \\ and Derong Wang ${ }^{1}$ \\ ${ }^{1}$ State Key Laboratory for Disaster Prevention \& Mitigation of Explosion \& Impact, PLA University of Science and Technology, \\ Nanjing 210007, China \\ ${ }^{2}$ Equipment Academy of Rocket Army, Beijing 100085, China
}

Correspondence should be addressed to Lang Li; lilang593@163.com and Pengxian Fan; fan-px@139.com

Received 10 April 2016; Accepted 12 July 2016

Academic Editor: Wei Zhou

Copyright (C) 2016 Lang Li et al. This is an open access article distributed under the Creative Commons Attribution License, which permits unrestricted use, distribution, and reproduction in any medium, provided the original work is properly cited.

\begin{abstract}
This paper presents experimental study on rockbursts that occur in deep underground excavations. To begin with, the boundary conditions for excavation in deep underground engineering were analysed and elastic adaptive boundary is an effective way to minimize the boundary effect of geomechanical model test. Then, in order to simulate an elastic adaptive loading boundary, Belleville springs were used to establish this loading boundary. With the aforementioned experimental set-ups and fabrication of similarity models for test, the phenomena of strain mode rockbursts were satisfactorily reproduced in laboratory. The internal stress, strain, and convergences of the openings of the model were instrumented by subtly preembedded sensors and transducers. Test results showed that, with an initial state of high stress from both upper layers' gravitational effects and in situ stress due to tectonic movements, the excavation brings a dramatic rise in the hoop stress and sharp drop in radial stress, which leads to the splitting failure of rock mass. Finally a rockburst occurred associated with the release of strain energy stored in highly stressed rock mass. In addition, the failure of the surrounding rock demonstrated an obvious hysteresis effect which supplies valuable guide and reference for tunnel support. Not only do these results provide a basis for further comprehensive experiments, but also the data can offer assisting aids for further theoretical study of rockbursts.
\end{abstract}

\section{Introduction}

With the rapid development of construction and the overwhelming demands for resources, the development and use of underground spaces gradually reach into deeper areas, including mines, tunnels, and nuclear waste disposal sites. With incremental increases in the buried depth of projects, we find that some nonlinear deformations and failure phenomena occur which are different from those in shallow rock engineering. Also, they cannot be satisfactorily explained by the traditional theory of continuum mechanics. The special phenomena such as rockbursts, zonal disintegration, and anomalously low friction have sparked widespread concerns in the international rock mechanics engineering community. The study of these problems has become an important issue in the past decades [1-4]. Generally, deep underground engineering is surrounded by a geological environment with high stress, high temperature, and high water pressure which change the mechanical properties of the deep rock mass and result in phenomena such as rockbursts happening more frequently. Rockbursts occurred frequently in the process of mining and the construction of hydraulic projects. They not only pose a threat to the safety of construction workers and equipment, but also affect the construction process. Thus the research on rockbursts is imperative.

Current theories, such as energy theory [5], stiffness theory $[6,7]$, strength theory [8], impact tendency theory [8$10]$, fracture mechanics theory $[11,12]$, and fractal theory [13], have made some progress in the field of rockbursts. Because rockbursts happen suddenly and even randomly to some extent, these theories still cannot satisfactorily predict the occurrence of rockbursts. Therefore, a clear understanding 
of the exact rockburst mechanism and defining the law of rockbursts and forecasting them remain as challenging tasks.

Many experiments have been performed all over the world including uniaxial tests $[7,14,15]$, biaxial loading tests $[16,17]$, and triaxial tests [18-25]. For example, Gu et al. [14] successfully simulated an ejective rockburst phenomenon in a uniaxial test. He et al. [21-23] studied the process of rockbursts on granite under high crustal stress. Many others combined loading tests and the loading due to human disturbance which have been conducted on rock specimens. They preliminarily come to the conclusion that dynamic loading disturbance is crucial to the occurrence of rockbursts. These tests have made great progress in the research of rockbursts, but there still exist the following weaknesses: (1) Most of the loading systems actively interfere with the failure process of the specimen. (2) In situ rockbursts, while under a three-dimensional stress state, take place because the excavation and unloading produce a free face of the opening which results in stress transformation and concentration. The above experiments produced stress strain paths that are not consistent with the stress transformation conditions of an in situ rockburst. (3) Most of the tests are based on the original rock, and the size is not big enough to satisfy the conditions. Stress concentration on the loading boundary usually leads to differences from the practical engineering. Owing to the problems listed above, laboratory studies on rockbursts have not achieved a breakthrough. What is more, many scholars have carried out research using the similar test model [26-29]. Zhou et al. [26] studied on mechanisms of slab buckling rockburst in deep tunnel using physical simulation experiment. Lu et al. [27] investigated rockburst induced by explosion stress wave at the chamber after excavation. Model test of rockburst has become an important means to study the mechanism of rockburst. However, they have not done a good job of reproducing the phenomenon of strain rockburst in the laboratory or they cannot give a complete change law for the internal stress and strain of excavation.

This paper reproduces a strain rockburst phenomenon using tests of similarity models. First, to simulate the initial stress state in deep rock mass more accurately, we suggest an elastic adaptive boundary and Belleville springs were used to establish this loading boundary. Second, by accurately simulating the process of excavating the tunnel, a free surface caused by excavation is produced, and the stress is converted due to the unloading of surrounding rock. Thus a more realistic simulation of the generation process of in situ rockbursts is carried out. The aim is to reproduce the rockburst phenomenon using tests of similarity models. Then a variety of means are used to monitor the whole occurrence and the development process of rockbursts. This can provide a basis for an experiment and data to support the further study of the initiation mechanism of rockbursts.

\section{New Loading Boundary of the Test Model}

2.1. Boundary Conditions. A finite size model to simulate the excavation problem in an infinite medium is generally used in a geotechnical test model. Boundary conditions are essential

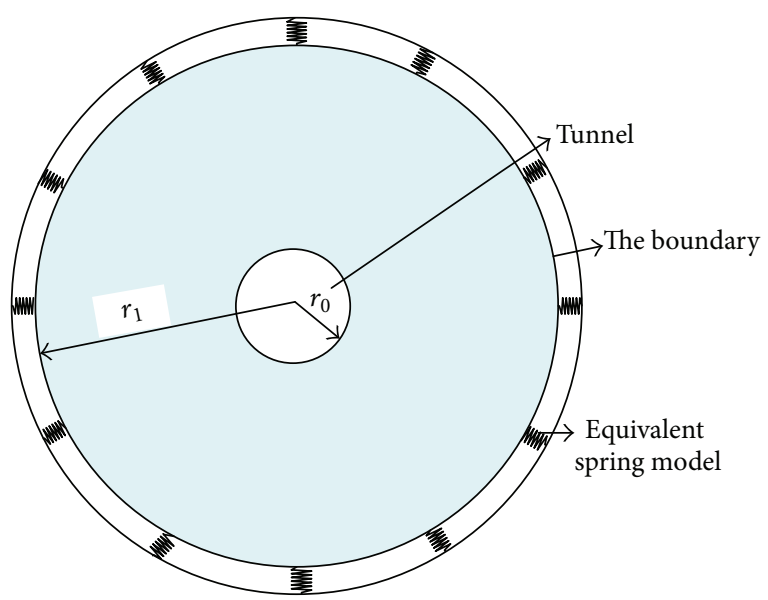

FIGURE 1: Equivalent spring model on the boundary of tunnel excavation.

for the success of the test. The excavation of the tunnel in practical engineering can be seen as creating a new opening with the radius $r_{0}$ in an infinite medium. It can be simplified as a plane strain problem. By taking a nearby area in rock mass as the research object, the rock mass is in direct contact with the tunnel with an area $r_{0}<r<r_{1}$ : $r_{1}$ usually reaching $6 \sim 8 r_{0}$ according to Liao et al. [30]. The materials outside this area $\left(r>r_{1}\right)$ can be seen as a continuous elastic medium. Its impact on the near field can be simulated by elastic elements. As a result, when creating a new opening the boundary can be equivalent to a spring model (Figure 1).

The current boundary conditions can be classified into two kinds: one is the displacement boundary condition; the other is the stress boundary condition. The former boundary is rigid, and its displacement is even, but the stress is not uniform. For homogeneous materials it can provide satisfactory test results, but for discontinuous and heterogeneous material like a rock mass it can provide nonuniform and uncertain stress on the boundary, and thus the initial stress state of rock mass cannot be easily simulated. To ensure a uniform stress field and a more accurate simulation test boundary, the other boundary is of greater significance. As the buried depth of underground engineering increases, the stress becomes high enough so that the effect of boundary conditions on test results is very significant. In addition, deep rock masses have energetic properties [31]. As a result, these two boundary conditions cannot guarantee strict similarity between the test model and the practical engineering. So it is necessary to explore the boundary conditions to further improve the credibility of the test model in deep underground engineering. An elastic adaptive boundary is presented by Haiming et al. [32] to minimize the boundary effect of geomechanical model test. Hence, when creating a new opening in the model shown in Figure 1, the rebound stiffness $k$ on the outer boundary with radius $r$ can be calculated from

$$
k=\frac{2 G}{r}=\frac{E}{(1+\nu) r},
$$




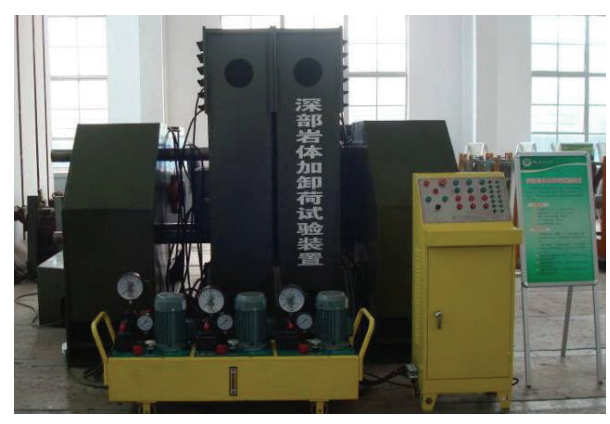

FIGURE 2: Deep rock mass loading and unloading test apparatus.

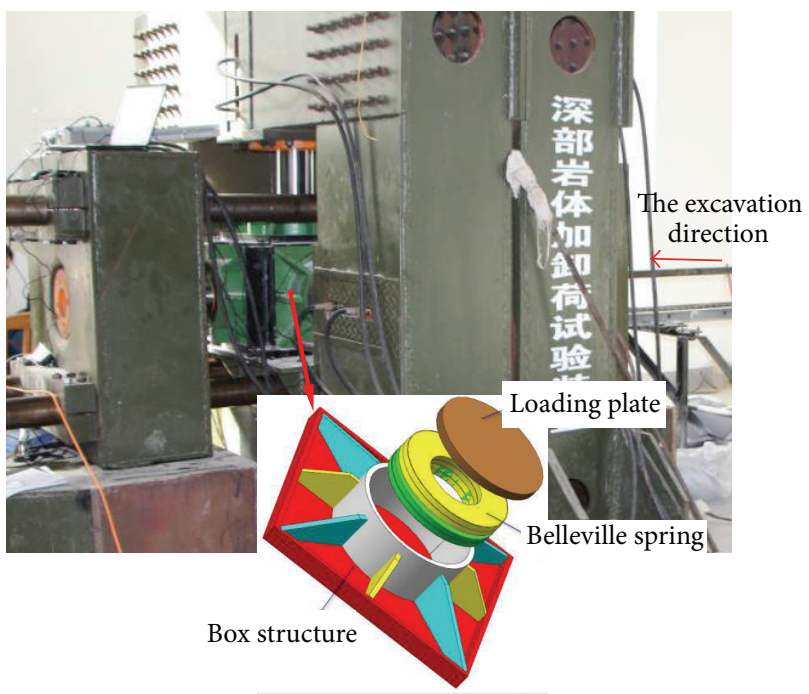

Figure 3: Schematic diagram of Belleville spring loading system.

where $v$ is Poisson's ratio, $G$ is the modulus of elasticity in shear, $E$ is elastic modulus. Therefore, during the period of the test model, the equivalent stiffness acting on the model's boundary by the loading devices should be equal to the rebound stiffness of the model due to excavation and unloading. This boundary condition is an effective way to minimize the boundary effect of geomechanical model test and is more consistent with the practical engineering.

\subsection{Physical Implementation of Elastic Adaptive Boundary.} A test apparatus for deep rock mass loading and unloading is used to simulate the initial in situ stress (Figure 2). The vertical direction and the left- and right-hand sides of the model are uniformly loaded by the hydraulic jack. A hydraulic jack is located at the excavation direction. The bottom and front face of the model are loaded by the reaction frame loading system. Because the parameters of equivalent materials are usually very low, the rebound stiffness on the boundary of model, according to the theory, is relatively less than the test device. Therefore, the stiffness of loading system must be reduced. Belleville springs are introduced to the loading system which are set between the cylinder and the loading plate. A schematic of this arrangement is presented in Figure 3 . The total pressure is provided by a hydraulic system.
TABLE 1: Belleville spring parameters.

\begin{tabular}{lcccccc}
\hline$D(\mathrm{~mm}) d(\mathrm{~mm})$ & $t(\mathrm{~mm})$ & $h_{0}(\mathrm{~mm})$ & $H_{0}(\mathrm{~mm})$ & $p(\mathrm{KN})$ & $f(\mathrm{~mm})$ \\
\hline 250 & 127 & 14 & 5.6 & 19.6 & 249 & 4.2 \\
\hline
\end{tabular}

The pressure is transferred to the model through compressed springs and elastic energy is stored in spring systems. In this case, the elastic boundary condition can be easily satisfied.

According to the theory, the equivalent stiffness of the loading device acting on the boundary should be equal to the rebound stiffness of the model. By considering the bearing capacity of the Belleville spring and stiffness requirements, we select the specifications of the Belleville spring to be $\phi 250 \times$ $127 \times 14 \mathrm{~mm}$. At the same time, the deformation range of the spring in the experiment is controlled within 10\% 75\% of its maximum compression stroke for safety. According to GB/T1972-2005 [33], the specific parameters of spring are shown in Table 1. And the stiffness value of a single $\phi 250 \mathrm{~mm}$ spring is $6.26 \times 10^{7} \mathrm{~N} / \mathrm{m}$. The rebound stiffness (per unit area) on the border of model when excavating is $8.9 \times 10^{8} \mathrm{~N} / \mathrm{m}^{3}$. The composite combination of Belleville springs is adopted. It consists of four and five superimposed springs and then superimposed on the two groups together according to the relative direction. The stiffness of the Belleville spring system and its equivalent stiffness acting on the model are $1.55 \times$ $10^{8} \mathrm{~N} / \mathrm{m}$ and $8.81 \times 10^{8} \mathrm{~N} / \mathrm{m}^{3}$, respectively, which can easily meet the theory [34].

To summarize, the test apparatus provides the following conditions at the boundary of the model: (1) the boundary can quickly supply the model with a rebound energy caused by excavation and provide the model with a proper stiffness; (2) stress can be adjusted automatically with the stiffness $k$ on the boundary.

\section{Test Design and Procedures}

3.1. Engineering Background. The transport tunnels of the Jinping II hydropower project are selected as the engineering prototype. This engineering project was located in the sloped terrain zone from the Tibetan Plateau to the Sichuan Basin of China. The two transport tunnels are about $17.5 \mathrm{~km}$ long and the cross-sectional sizes of the A and B tunnels are 5.5 $\times 4.5 \mathrm{~m}^{2}$ and $6 \times 5 \mathrm{~m}^{2}$, respectively, with a line spacing of $35 \mathrm{~m}$. Most of the tunnel's buried depth is more than $1500 \mathrm{~m}$. The lithology of the nature rock is mostly Triassic, Limestone, and maximum tunnel depth is $2375 \mathrm{~m}$. Rockbursts did occur many times during construction.

3.2. Test Scheme Design. Strain rockburst usually occurs in intact rock and is caused by deformation and failure of the rock mass [35]. In this study the test does not consider faults, joints, and cracks in the rock mass. The rock is assumed to be intact. The model dimensions (length $\times$ width $\times$ height) are $0.88 \mathrm{~m} \times 0.4 \mathrm{~m} \times 0.4 \mathrm{~m}$. To facilitate data analysis and summarize the formulas, the opening tunnel is defined as round with a diameter of $80 \mathrm{~mm}$ and excavation depth of $700 \mathrm{~mm}$. The measuring points for stress, strain, and temperature sensors are shown in Figure 4. 


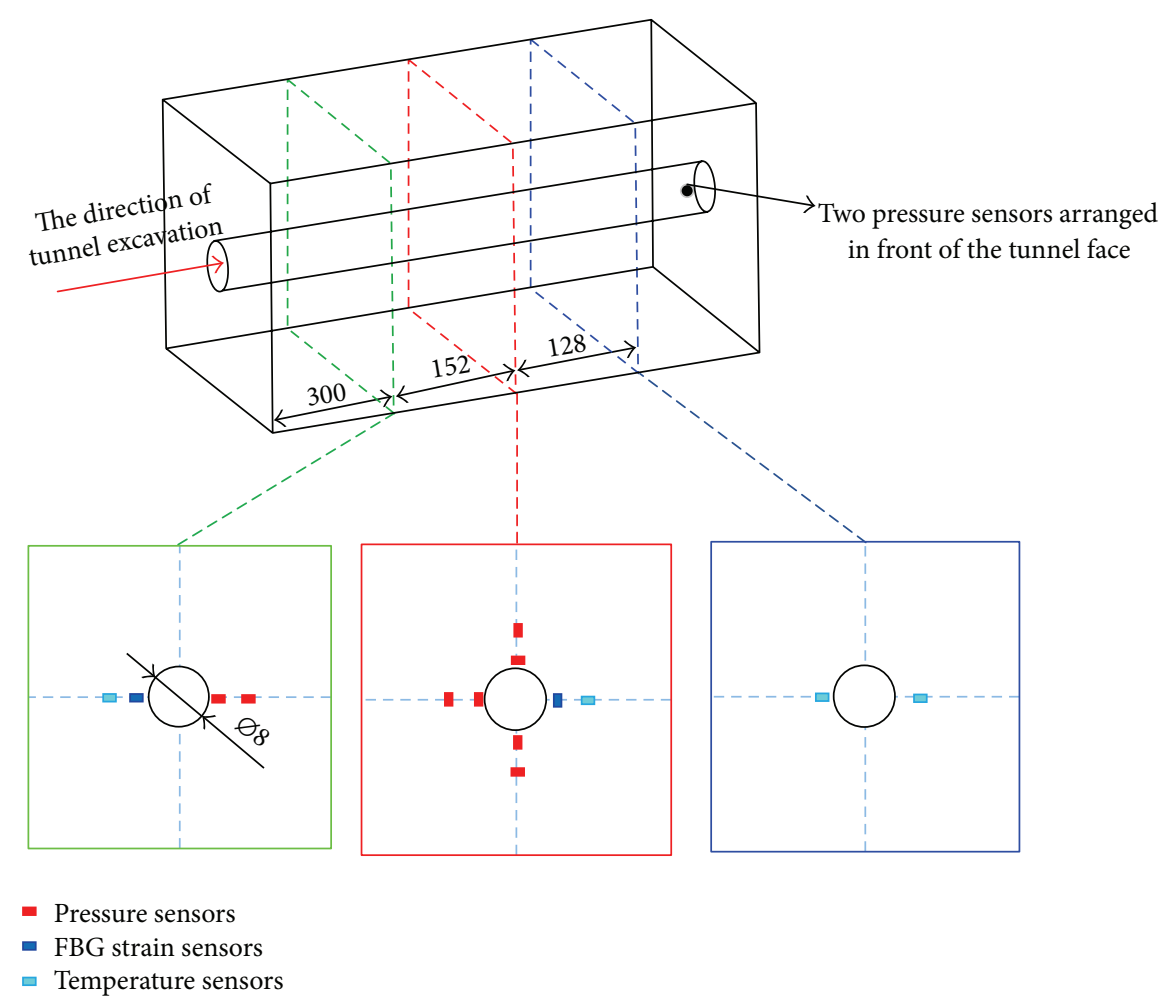

FIGURE 4: Stress, strain, and temperature sensors measuring points.

TABLE 2: The ratio of equivalent materials.

\begin{tabular}{lccccc}
\hline Components & Barite sand & Quartz sand & Barite powder & Rosin & Alcohol \\
\hline Ratio & $45 \%$ & $5 \%$ & $50 \%$ & $0.5 \%$ & $4.5 \%$ \\
\hline
\end{tabular}

3.3. Equivalent Materials. At present the similarity criterion generally uses the elastic theory and dimensional analysis method. Specifically, the geometric similarity scale $C_{l}$ and bulk density similarity scale $C_{\gamma}$ of the experimental model are 75 and 1, respectively. Scales of other parameters can be deduced by analogy to the equilibrium; geometric and physical equations, boundary conditions, and Newton's second law are expressed as:

$$
\begin{gathered}
C_{\sigma}=C_{E}=C_{\delta}=75, \\
C_{t}=\sqrt{75}, \\
C_{\varepsilon}=C_{f}=C_{\varphi}=C_{\mu}=1,
\end{gathered}
$$

where $C_{\sigma}, C_{l}, C_{\gamma}, C_{E}, C_{\varepsilon}, C_{\delta}, C_{t}, C_{f}, C_{\varphi}$, and $C_{\mu}$ denote the similarity scales of stress, geometry, density, elastic modulus, strain, displacement, time, friction coefficient, friction angle, and Poisson's ratio, respectively.

Rockbursts generally occur in the hard and brittle rock. To simulate marble according to the similarity criteria, we adopt resin-based equivalent materials that are developed by Fan et al. [36]. This material uses resin as the bonding agent, barite ore and quartz sand as the aggregate, and barite powder as the fine aggregate. It is a kind of brittle materials with lowstrength. The mould, specimens, curing of sample, and the mechanical parameters test such as the uniaxial compression test and shear test are shown in Figure 5. The proportion of each component used in the experiment is shown in Table 2 and the unit of each component ratio is weight percentage. The physical and mechanical parameters of the natural rock and equivalent material are shown in Table 3. It can be seen that the materials meet the theoretical requirements and do a good job of simulating the marble of the engineering prototype.

3.4. Preparation of the Sample Model. The model uses the method of layered filling and compaction. To ensure a uniform stress field of the model at the boundary, flexible rubber is positioned at the contact areas between the model and test device. To decrease the friction effect, a layer of PTFE film is pasted on the other side of the flexible rubber (Figure 6(a)). The equivalent material is compressed to a dense state at $2 \mathrm{MPa}$ pressure by two hydraulic jacks in the vertical direction. To avoid the formation of an obvious interface and make an effective bond the model with the material filled the next layer, and alcohol solution is sprayed on the surface of the model. Its surface is shaved with a steel rake after the softening of the material model. Then the next layer of materials is joined until the entire model is completed. The internal pressure in the model is measured 


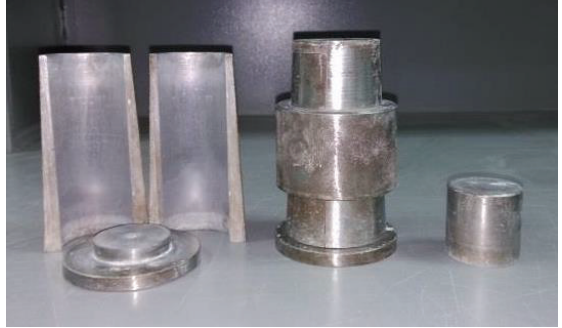

(a)

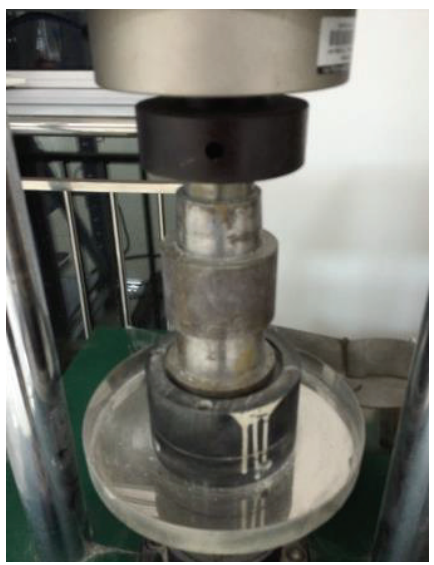

(c)

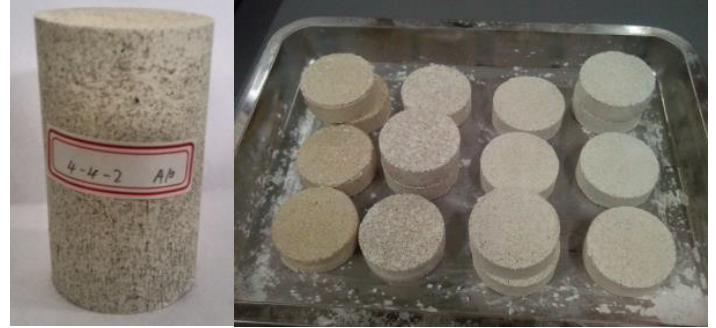

(b)

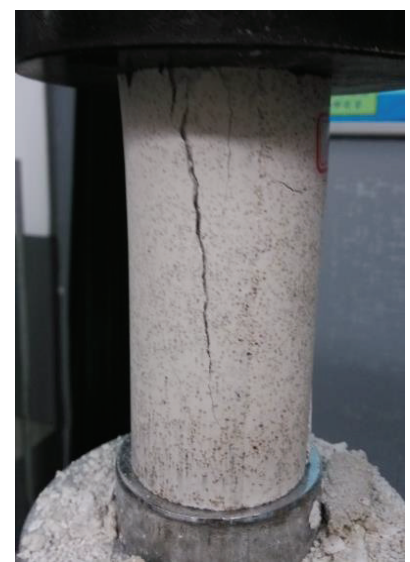

(e)

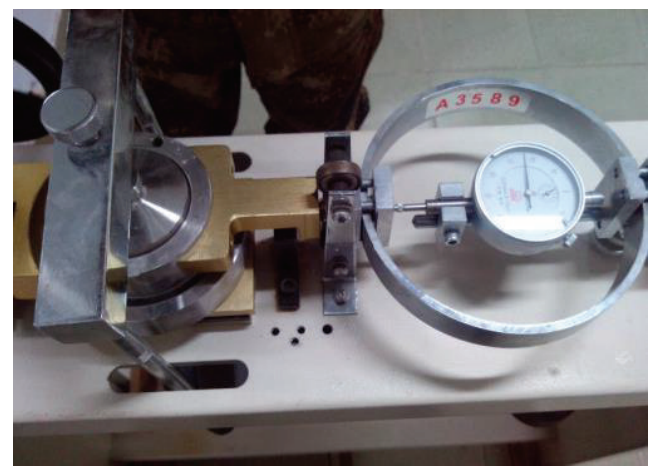

(f)

FIGURE 5: Equivalent materials and mechanical experiments: (a) the mould; (b) sample of equivalent materials; (c) sample preparation; (d) maintenance of the sample; (e) uniaxial compressive test of sample; (f) shearing test of the sample.

TABLE 3: Physical and mechanical parameters of the prototype and model.

\begin{tabular}{lcccccc}
\hline Material types & $\begin{array}{c}\text { Dry density } \\
\text { KN/m3 }\end{array}$ & $\begin{array}{c}\text { Elastic } \\
\text { modulus/MPa }\end{array}$ & $\begin{array}{c}\text { Compressive } \\
\text { strength/MPa }\end{array}$ & $\begin{array}{c}\text { Tensile } \\
\text { strength/MPa }\end{array}$ & $\begin{array}{c}\text { Cohesion/MPa } \\
\text { Internal } \\
\text { friction angle }\end{array}$ \\
\hline Marble & 27.7 & 25300 & 89.2 & 4.95 & 4.24 & $53.1^{\circ}$ \\
\hline $\begin{array}{l}\text { Equivalent } \\
\text { materials }\end{array}$ & 27.7 & 369.6 & 1.1 & 0.07 & 0.06 & $50.7^{\circ}$ \\
\hline
\end{tabular}

by DZ-I pressure sensors, with the following dimensions: thickness $7 \mathrm{~mm}$; diameter $17 \mathrm{~mm}$ (Figure 6(b)). The internal strain measurement used FCC-Y FBG sensors (Figure 6(c)). First, FBG sensors are encapsulated in the equivalent material blocks and then embedded in the model after the calibration test. Because the FBG sensors are particularly sensitive to temperature, four temperature sensors are placed in the model to monitor the temperature during the process of excavation. The temperature changes very little during the test. The temperature in model ranges between 13.8 and $14.7^{\circ} \mathrm{C}$. In the process of excavation, the temperature is maintained between 14.4 and $14.5^{\circ} \mathrm{C}$. For the FBG strain sensor, the strain varies by roughly $10 \mu \varepsilon$ in the sensor for each degree change in temperature. Therefore, the variation 


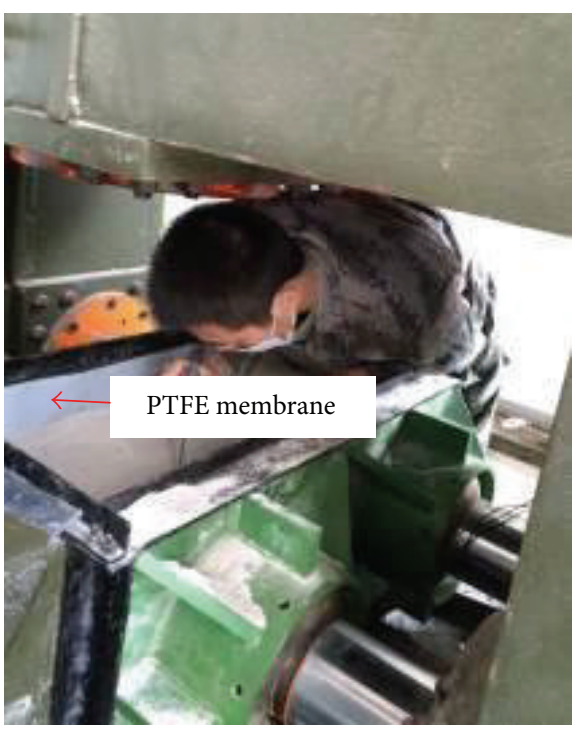

(a)

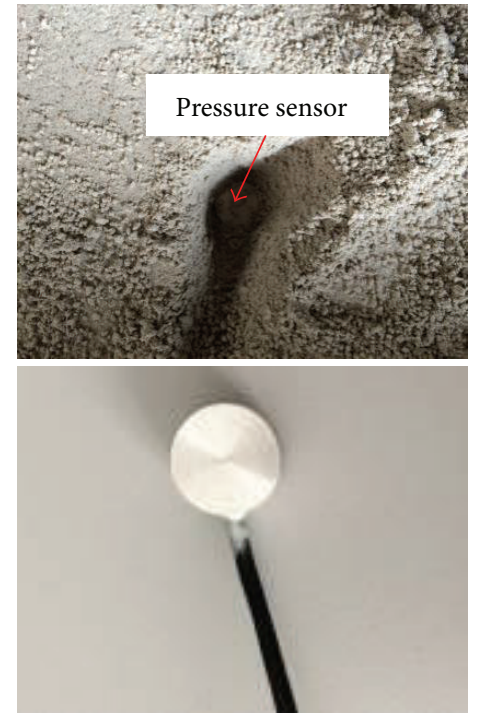

(b)

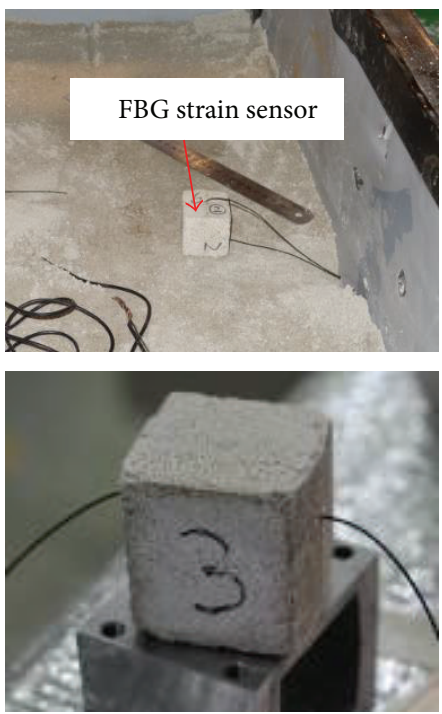

(c)

FIGURE 6: Fiber grating strain (FBG) sensor and pressure sensor embedded process: (a) layered filling of the model; (b) DZ-I pressure sensors; (c) FCC-Y FBG strain sensors.

of FBG strain sensor's wavelength is basically due to the changing stress caused by the model.

3.5. Simulation of the In Situ Stress and Excavation. We set the underground engineering construction to have a buried depth of $2375 \mathrm{~m}$ as an example. The vertical in situ stress is given by

$$
\sigma=\gamma H=64.4 \mathrm{MPa} .
$$

To simulate the in situ stress, a pressure of $0.86 \mathrm{MPa}$ needs to be applied to the model. The excavated tunnel is $70 \mathrm{~cm}$ long and $8 \mathrm{~cm}$ in diameter. According to the similarity criterion, each excavation length is $7 \mathrm{~cm}$ and it takes 5 minutes to finish the excavation. The next step of excavation is started 15 minutes later. The spiral drill pipe driven by the motor that simulates the excavation and unloading is adopted to create a new opening in the model. The internal stress, strain, and temperature are monitored during excavation process. Excavation equipment and internal stress and strain monitoring system are shown in Figure 7. After the excavation finished, the load acting on the model's boundary is maintained for three days. At the same time, stress, strain, temperature, and tunnel convergence are monitored. The residual deformation and failure models are recorded after the dismantling of the test apparatus.

\section{Test Results and Discussion}

4.1. Internal Pressure. The problem of an excavated circular tunnel can be simplified as a plane strain problem. The radial pressure points, which are 2 and $8 \mathrm{~cm}$ from the wall as calculated by elastic theory, reduce to $0.56 \gamma \mathrm{H}$ and $0.89 \gamma \mathrm{H}$, respectively. The circumferential pressure points, which are 2 and $8 \mathrm{~cm}$ from the wall, increase to $1.44 \gamma \mathrm{H}$ and $1.11 \gamma H$, respectively. Figures 8-10 show the changes of the pressure curve during the process of excavation. According to the curve, the initial pressure in each point is close to the initial in situ stress $0.86 \mathrm{MPa}$, which roughly satisfied the requirement of simulating the initial in situ stress environment for practical engineering. The pressure changing law of the surrounding rock during the excavation is similar to that calculated by elastic theory but also displays some new phenomena.

The measurement results of circumferential pressure during the excavation are shown in Figure 8. It can be seen from the figure that the values of the hoop pressure adjust gradually with the process of excavation and unloading, showing a trend of gradual increase. When the excavation section was just at the position of the sensors, the pressure increased suddenly and rose to the maximum value. For example, for the measurement points 2 and $8 \mathrm{~cm}$ from the wall, the pressure increases from the original values of 0.9 and $0.98 \mathrm{MPa}$ to 1.47 and $1.4 \mathrm{MPa}$, respectively. According to elastic theory, the stress growth amplitude is therefore $44 \%$ and $11 \%$, respectively, which are less than the measurement values of $63.3 \%$ and $42.9 \%$, respectively, in the same position of the test. This may be related to the high stress environment of deep rock mass or some mildly nonelastic behavior of the model material which results in a greater effective area. In addition, continuous excavation of the tunnel could also lead to a continual increase in pressure. When the hoop stress reaches the peak value after a certain period of time, the pressure falls sharply. The pressure $2 \mathrm{~cm}$ away from the wall decreases from 1.47 $\mathrm{MPa}$ to $0.89 \mathrm{MPa}$. The pressure $8 \mathrm{~cm}$ away from the wall suddenly decreases from $1.4 \mathrm{MPa}$ to $0 \mathrm{MPa}$. This fact shows that the model at this point may be damaged or may have become loose due to possible local failure induced by extensional strain. 


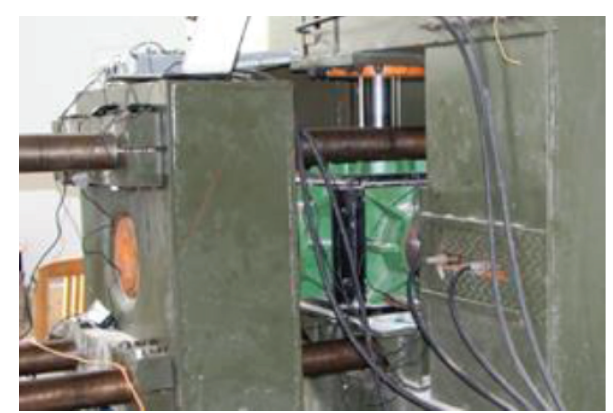

(a)

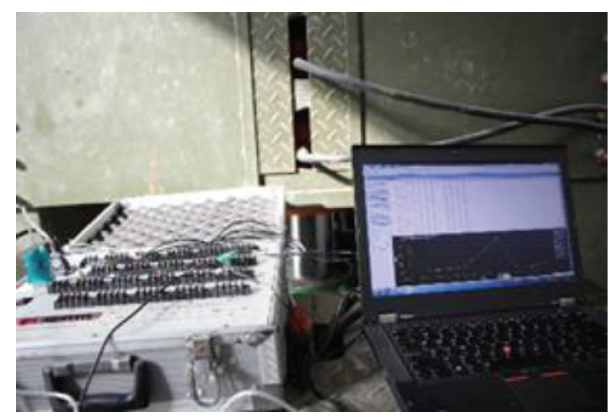

(c)

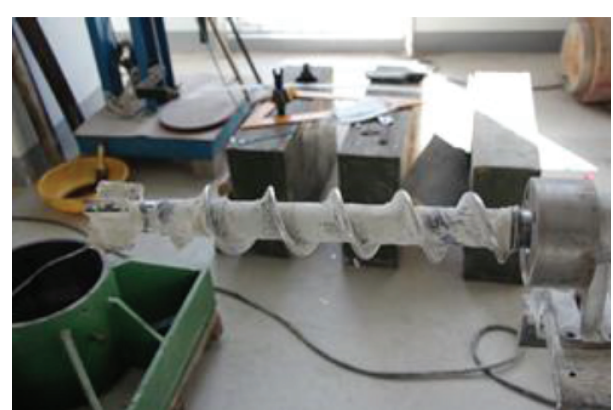

(b)

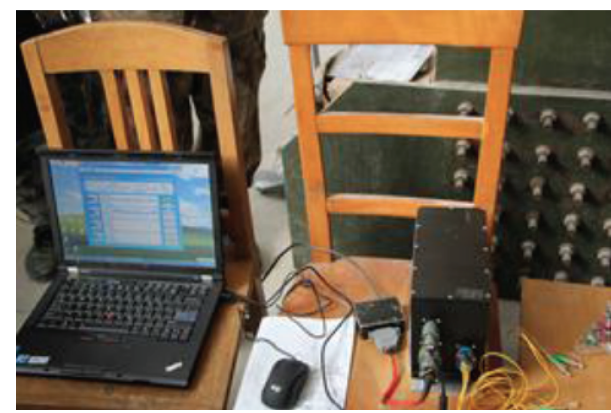

(d)

FIGURE 7: The process of test: (a) the process of loading; (b) the drill and excavation process; (c) internal pressure monitoring system; (d) FBG strain sensor monitoring system.

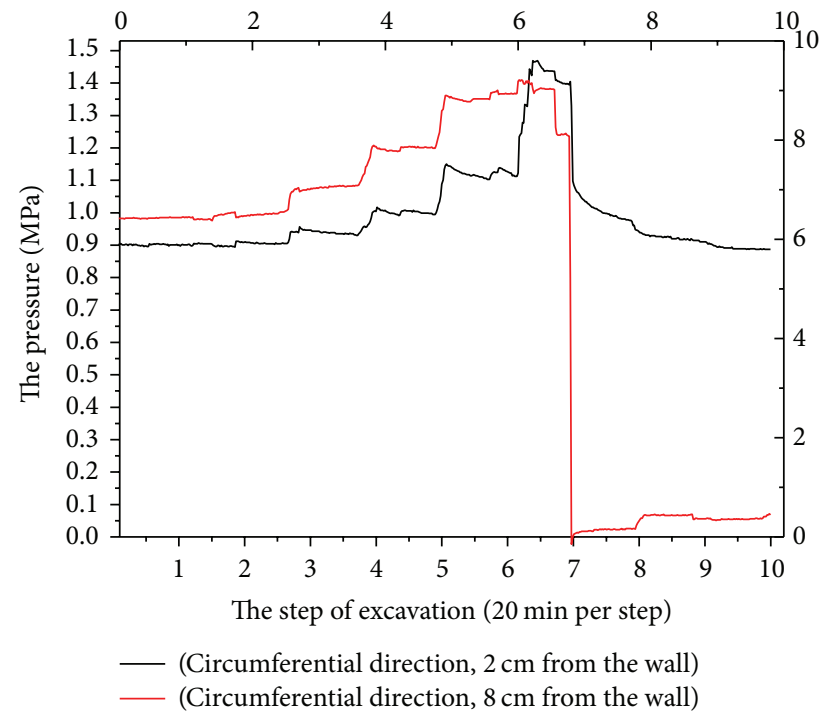

FIgURE 8: Hoop pressure change curve.

The pressure curve in the radial direction during the excavation is plotted in Figure 9. At the measurement points 2 and $8 \mathrm{~cm}$ from the wall, the pressure reduces from the original values of 0.96 and $0.92 \mathrm{MPa}$ to 0.2 and $0.65 \mathrm{MPa}$, respectively. The amplitudes of the stress decrease for these two points are $79.2 \%$ and $29.3 \%$, respectively. According to elastic theory, the amplitudes of the stress in these two points decrease $44 \%$ and $11 \%$, respectively. The unloading of pressure in the radial direction induced by excavation is more apparent. The

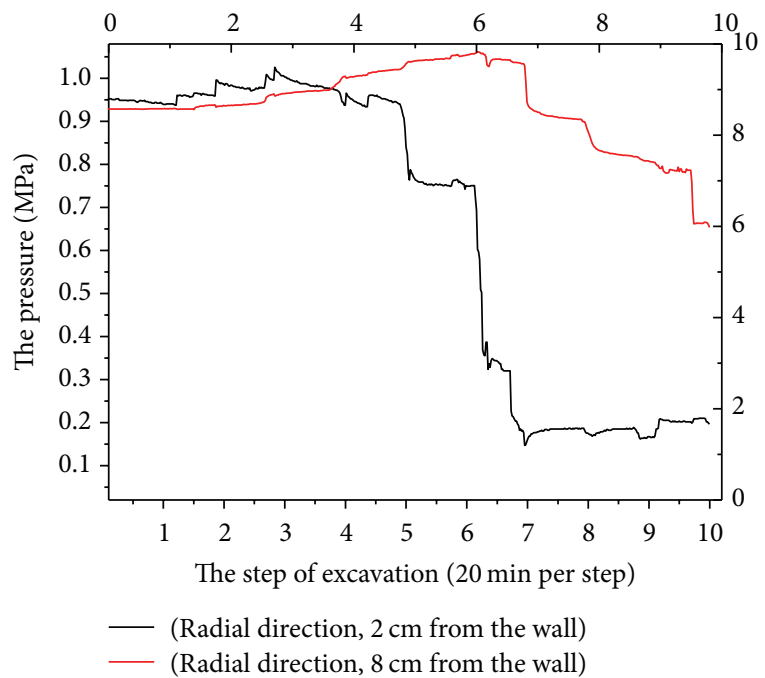

FIGURE 9: Radial pressure change curve.

pressure at the point $2 \mathrm{~cm}$ away from the wall decreases sharply; this result shows that the model at this point may be damaged or become loose. So its pressure reduces to $0.2 \mathrm{MPa}$. In addition, the excavation process will lead to continuous loading along the circumferential direction and unloading along the radial direction in the surrounding rock mass. And the pressure variation is greater than the theoretical calculation, which is, therefore, prone to cause the failure of the surrounding rock and induce geological disasters. 


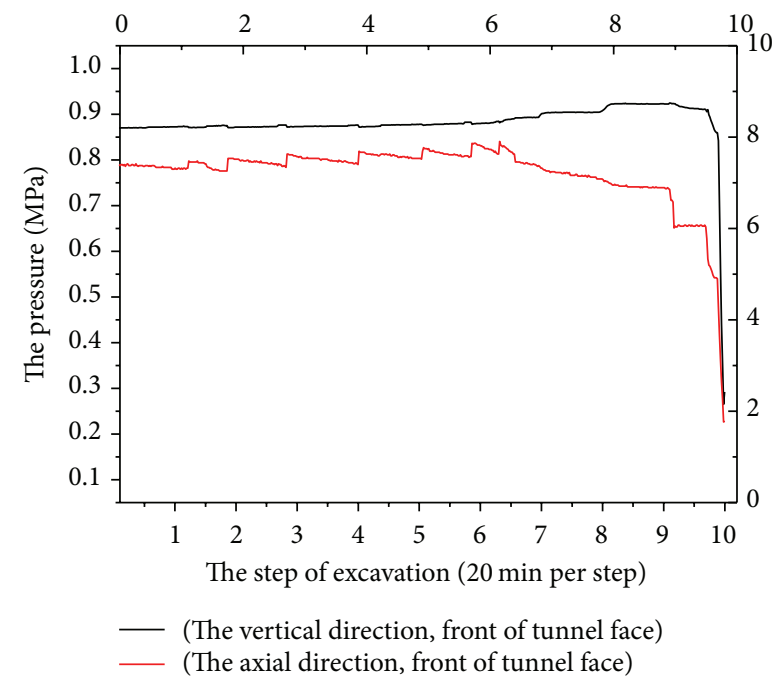

FIGURE 10: Internal pressure of measuring points (front of tunnel face).

The pressure curve in front of the tunnel face during the excavation is shown in Figure 10. There is little change in the pressure during the excavation. When the excavation section is close to the position of the sensors, the pressure in vertical direction decreases sharply from the original $0.87 \mathrm{MPa}$ to $0.29 \mathrm{MPa}$, while the pressure in axial direction decreases gradually from the original $0.79 \mathrm{MPa}$ to $0.23 \mathrm{MPa}$.

4.2. Strain Measurement. Two FBG strain sensors were embedded $2 \mathrm{~cm}$ from the wall along the radial and circumferential directions in the model. Figure 11 shows the strain curve of sensors during the process of test at each measuring point.

At the beginning stage of excavation, the two measurement points are in a relatively stable state. With the onset of excavation and unloading, the pressure of the surrounding rock gradually adjusts. The wavelength of the sensor in the hoop direction gradually decreases beginning with the third step of excavation. This is because of the increase in hoop stress due to excavation. The wavelength decreases the most at the sixth step of excavation. The maximum strain in hoop direction reaches $1268 \mu \varepsilon$. On the other hand, the wavelength of the sensor in the radial direction suddenly increases during the fifth step of excavation. The corresponding strain reaches $-1025 \mu \varepsilon$. The maximum radial strain reaches $-2528 \mu \varepsilon$ during the excavation. According to elastic theory, the radial and circumferential strains, which are $2 \mathrm{~cm}$ from the wall, are $-1272 \mu \varepsilon$ and $1272 \mu \varepsilon$, respectively. The measured variation rules of stress and strain are in good agreement with theoretical analysis, and the strain in the hoop direction is very close to the theoretical value.

4.3. Convergence of the Tunnel. Based on the small angle principle (Figure 12), the angle variation $\Delta \beta$ at the same point was measured by the Leica Total Station. The horizontal distance was measured from the marked points to the Total
Station using tape. So the displacement $\delta$ can be calculated by [37]

$$
\delta=\frac{\Delta \beta}{(\rho \cdot D)},
$$

where $\Delta \beta$ is angle variation between the two measurements, the constant coefficient $\rho$ denotes the relationship between a degree and a radian and is approximately equal to 206264.8 , and $D$ is the distance between the measuring point and observation point.

The displacement variations of the tunnel wall with time after excavation are shown in Figure 13. It is easy to see that the initial deformation of the tunnel grew steadily and then increased sharply, finally becoming stable. After $60 \mathrm{~h}$, the displacements became stable, with convergences of 0.37 , 0.53 , and $0.55 \mathrm{~mm}$ at the roof, left-hand wall, and right-hand wall, respectively. The displacements corresponding to actual engineering are $27.75,39.75$, and $41.25 \mathrm{~mm}$. The change rule of displacement in the tunnel agrees with the actual engineering excavation.

4.4. The Deformation and Failure of Surrounding Rock. In the construction of Jinping II hydropower project, the surrounding rock shows obvious brittle failure characteristics, such as plate crack phenomena and rockbursts. The occurrences of these kinds of failure phenomena are obvious during the experiment. Polyaxial or true triaxial tests had been performed by Addis et al. [38] to investigate the stability of model boreholes. And Zhou et al. [26] pointed out that there is a strong correlation between plate crack phenomena and rockbursts and that slab cracking is a precursor of rockbursts. In addition, the failure of the surrounding rock in the deep underground openings showed an obvious hysteresis effect. Obvious damage phenomena of the surrounding rock began to emerge 8 hours after excavation. The plate fracture failure of the surrounding rock occurred at the top and right side of the tunnel (Figure 14), which agrees with the practical engineering. Then two days after the excavation the ejection of fractured blocks into the hole occurred, which we interpreted as reproduction of a severe rock burst (Figure 15).

From further analyses we can conclude that the stress level, under the deep rock mass environment, is usually very high. At the moment of creating a new opening, the increase in the hoop stress and the unloading of the radial stress result in a splitting tensile failure of the surrounding rock mass. Later, with further adjustment of the interior pressure and continual excavation and unloading, the surrounding rock gradually becomes damaged, and the peak of hoop stress transfers to the deep environment. After a certain period of time, the rocks surrounding the interior form a "support pressure zone." In the "range of the support pressure zone," the circumferential stress reaches the maximum value, while near the tunnel wall the surrounding rock loses a certain bearing capacity due to the gradual destruction. Thus, rockbursts suddenly occur $42 \mathrm{~cm}$ away from the model boundary. In the seventh step of excavation the pressure suddenly dropped to zero based on the measurement results, which indicated some damage was produced in the rock. However, 


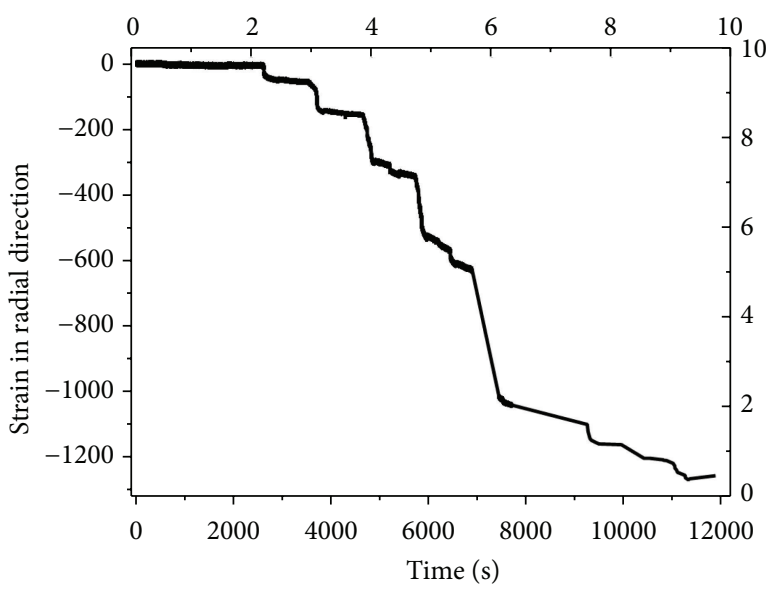

(a)

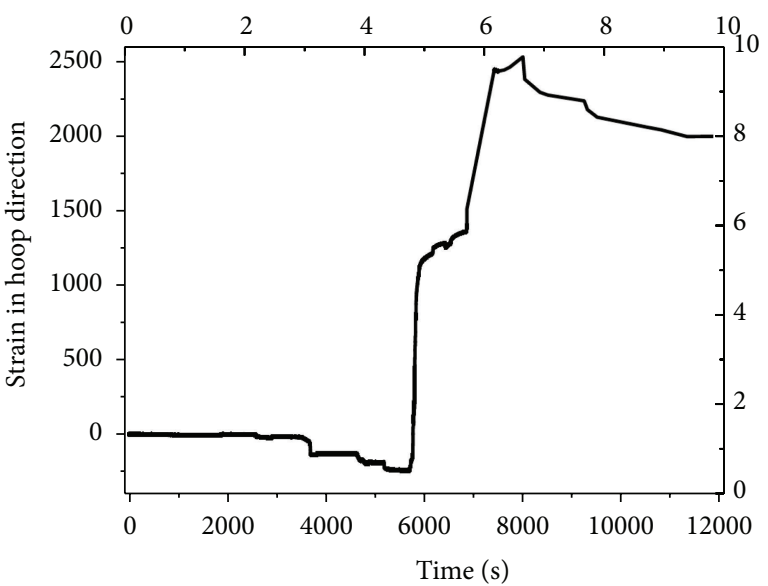

(b)

FIGURE 11: Internal strain change curve: (a) strain in radial direction; (b) strain in hoop direction.

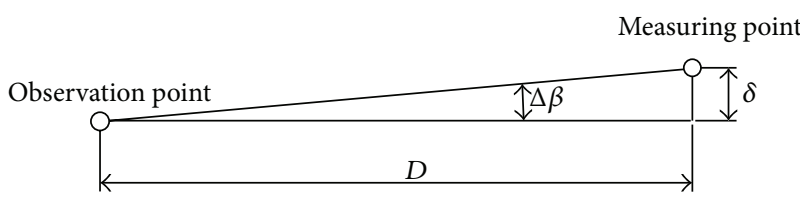

Figure 12: Displacement measuring principle of small angle method.

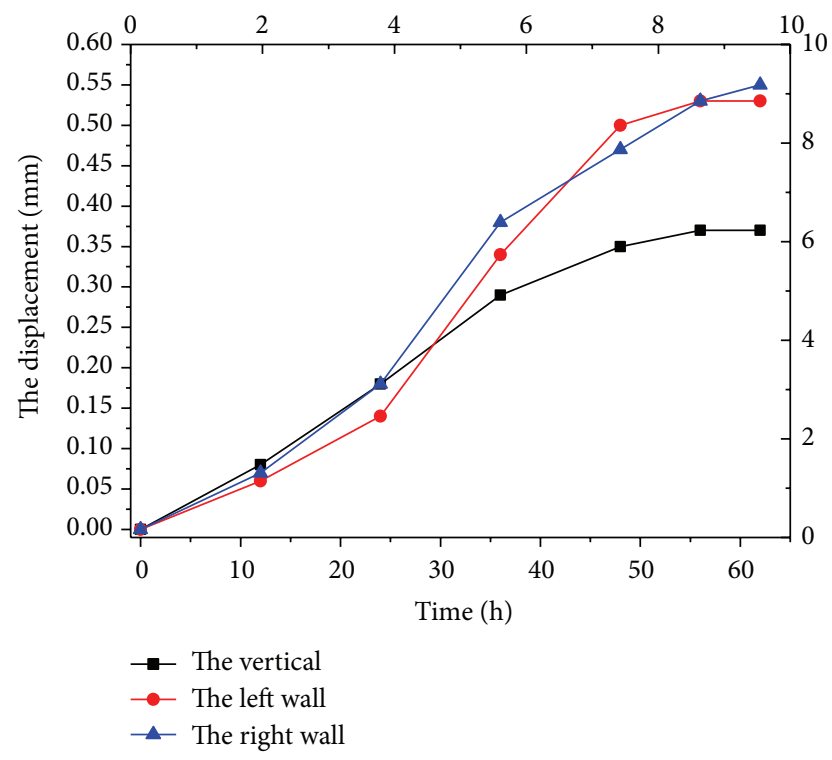

FIGURE 13: The convergence curve of tunnel wall after the excavation.

rockbursts would not happen until a period of time after the excavation. With further adjustment of the surrounding rock pressure and potential energy concentration, rockbursts would occur suddenly. According to the ejected volume of equivalent material, this is a serious rockburst because the ejection volume is large. To sum up, a rockburst is a complex dynamic disaster phenomenon which occurs in the rock mass with high in situ stress induced by continual disturbances due to the excavation. The excavation brings a dramatic rise in the hoop stress and drop sharp in radial stress, which leads to the splitting failure of rock mass. Finally a strain model rockburst suddenly occurred associated with the release of strain energy stored in highly stressed rock mass.

\section{Conclusions and Prospects}

Through a preliminary test of a model for rockbursts simulated by low-strength brittle equivalent materials we conclude the following.

(1) Based on elastic adaptive loading boundary, Belleville springs are introduced to the loading apparatus. It is a new loading boundary of the test model which can minimize the boundary effect of geomechanical model test. By adjusting the spring system, the stiffness of test apparatus can be adjusted conveniently. It can quickly supply the model with a rebound energy caused by excavation and provide the model with a proper stiffness. Besides, stress can be adjusted automatically at the boundary.

(2) Owing to the excavation and unloading, there is a stress distribution and energy-dispersion process in the surrounding rock. At a distance of 2 and $8 \mathrm{~cm}$ from the tunnel wall, the radial pressure reduces from the original values 0.96 and $0.92 \mathrm{MPa}$ to 0.2 and $0.65 \mathrm{MPa}$, respectively, and the hoop pressure increases from 0.9 and $0.98 \mathrm{MPa}$ to 1.47 and 1.4 MPa, respectively. The maximum values of the radial and hoop strain reach to $2528 \mu \varepsilon$ and $1268 \mu \varepsilon$ during the process of the excavation, respectively. The convergences at the vertical, left-hand, and right-hand side of the wall in the tunnel after excavation were $0.37,0.53$, and $0.55 \mathrm{~mm}$, respectively. The excavation process will lead to continuous loading along the hoop direction and unloading along the radial direction in the surrounding rock mass. The fact that pressure variation in the test is greater than the theoretical calculation more easily leads to the failure of surrounding rock.

(3) In the process of the test model, the brittle failure phenomenon of surrounding rock can be observed. The failure of the surrounding rock in deep underground openings 

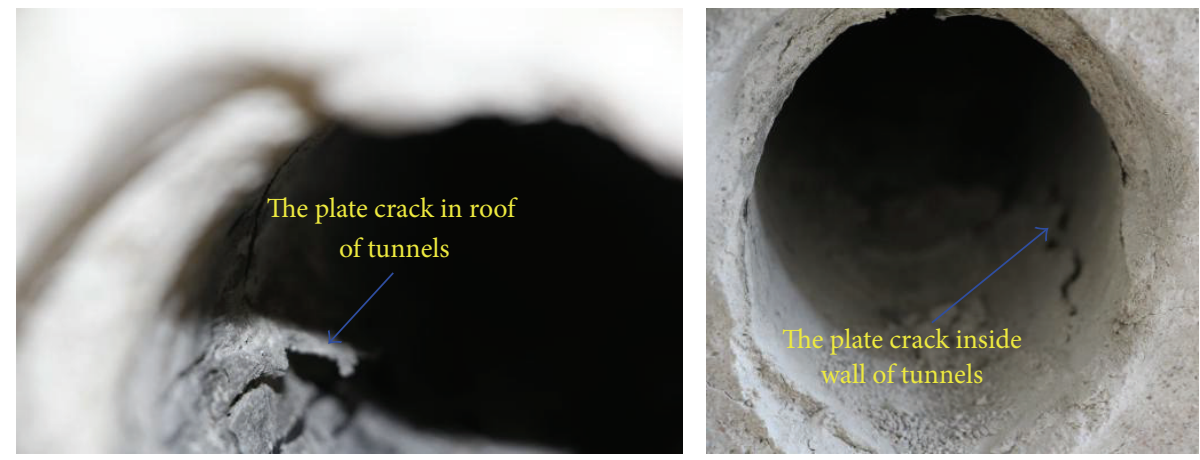

FIGURE 14: The plate cracking phenomenon.
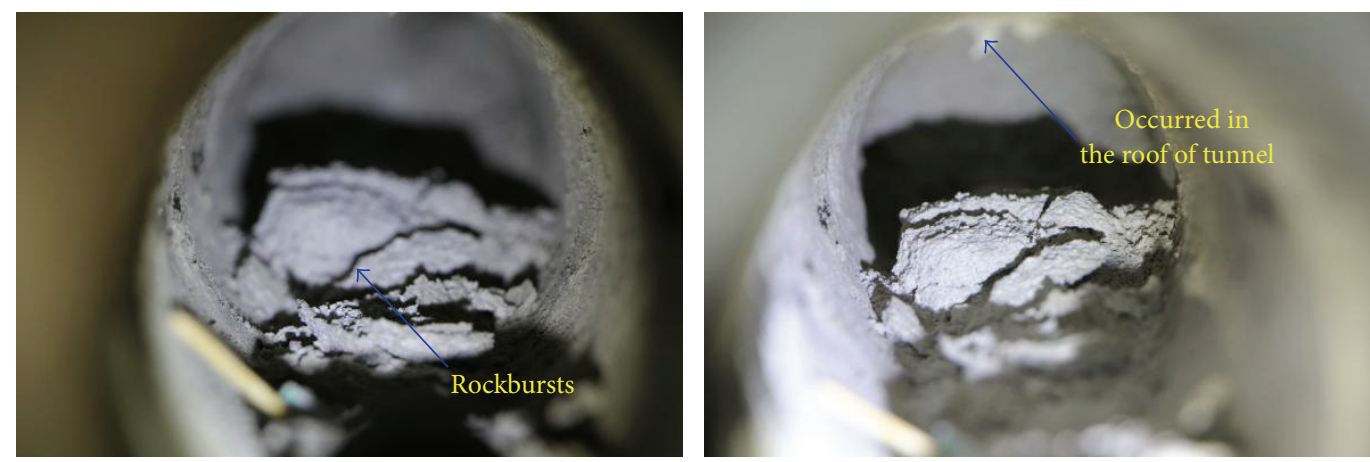

FIGURE 15: Rockbursts in model test.

demonstrated an obvious hysteresis effect. The mechanism of strain rockbursts can be interpreted as follows: with an initial state of high stress in rocks, the excavation brings a dramatic rise in the hoop stress and sharp drop in radial stress, which leads to the splitting failure of rock mass. Finally a strain model rockbursts occurred suddenly associated with the release of strain energy stored in highly stressed rock mass.

These results provide a basis for experiment and data to support the theoretical study of rockbursts. However, there is still some work to be done. The influence of stiffness of the test device on the destruction of the surrounding rock should be further investigated during excavation. To obtain more information of the dynamic mechanical parameters for rockbursts, the number of stress and strain measuring points should be increased.

\section{Competing Interests}

The authors declare no competing interests.

\section{Acknowledgments}

This study was financially supported by the National Basic Research Program of China (973 Program: 2013CB036005), the National Key Scientific Instrument and Equipment Development Project (no. 51527810), and the State Key Laboratory of Coal Resources and Safe Mining, CUMT (no. 14KF02).

\section{References}

[1] W. Blake, "Rock-burst mechanics," The Colorado School of Mines, vol. 67, no. 1, 1972.

[2] M. Kurlenya, V. Oparin, and V. Vostrikov, "Effect of anomalously low friction in block media," Journal of Applied Mechanics and Technical Physics, vol. 40, no. 6, pp. 1116-1120, 1999.

[3] Q. H. Qian, "New developments of rock engineering and technology in China," in Proceedings of the 12th ISRM International Congress on Rock Mechanics, Harmonising Rock Engineering and the Environment, pp. 57-61, Taylor and Francis Group, Beijing, China, October 2011.

[4] E. I. Shemyakin, G. L. Fisenko, M. V. Kurlenya et al., "Zonal disintegration of rocks around underground workings, part 1: data of in situ observations," Soviet Mining, vol. 22, no. 3, pp. $157-168,1986$.

[5] N. Cook, "The basic mechanics of rockbursts," Journal of the Southern African Institute of Mining and Metallurgy, vol. 63, pp. 71-81, 1963.

[6] N. Cook, "A note on rockbursts considered as a problem of stability," Journal of the Southern African Institute of Mining and Metallurgy, vol. 65, no. 3, pp. 437-446, 1965.

[7] M. D. G. Salamon, "Stability, instability and design of pillar workings," International Journal of Rock Mechanics and Mining Sciences \& Geomechanics Abstracts, vol. 7, no. 6, pp. 613-631, 1970.

[8] E. Hoek and E. T. Brown, Underground Excavations in Rock, Institution of Mining and Metallurgy, 1980. 
[9] A. Kidybiński, "Bursting liability indices of coal," International Journal of Rock Mechanics and Mining Sciences, vol. 18, no. 4, pp. 295-304, 1981.

[10] J.-A. Wang and H. D. Park, "Comprehensive prediction of rockburst based on analysis of strain energy in rocks," Tunnelling and Underground Space Technology, vol. 16, no. 1, pp. 49-57, 2001.

[11] A. V. Dyskin and L. N. Germanovich, "Model of rockburst caused by cracks growing near free surface," Rockbursts and Seismicity in Mines, vol. 93, no. 1, pp. 69-75, 1993.

[12] S. Nemat-Nasser and H. Horii, "Compression-induced nonplanar crack extension with application to splitting, exfoliation, and rockburst," Journal of Geophysical Research, vol. 87, no. 8, pp. 6805-6821, 1982.

[13] H. Xie and W. G. Pariseau, "Fractal character and mechanism of rock bursts," International Journal of Rock Mechanics and Mining Sciences and, vol. 30, no. 4, pp. 343-350, 1993.

[14] J. C. Gu, J. Fan, F. L. Kong, K. T. Wang, J. M. Xu, and T. Wang, "Mechanism of ejective rockburst and model testing technology," Chinese Journal of Rock Mechanics and Engineering, vol. 33, no. 6, pp. 1081-1089, 2014 (Chinese).

[15] S. P. Singh, "The influence of rock properties on the occurrence and control of rockbursts," Mining Science and Technology, vol. 5, no. 1, pp. 11-18, 1987.

[16] M. Barquins and J.-P. Petit, "Kinetic instabilities during the propagation of a branch crack: effects of loading conditions and internal pressure," Journal of Structural Geology, vol. 14, no. 8-9, pp. 893-903, 1992.

[17] P. S. Steif, “Crack extension under compressive loading," Engineering Fracture Mechanics, vol. 20, no. 3, pp. 463-473, 1984.

[18] K. H. Höfer and K. Thoma, "Triaxial tests on salt rocks," International Journal of Rock Mechanics and Mining Sciences \& Geomechanics Abstracts, vol. 5, no. 2, pp. 195-196, 1968.

[19] H. B. Li, J. Zhao, and T. J. Li, "Triaxial compression tests on a granite at different strain rates and confining pressures," International Journal of Rock Mechanics and Mining Sciences, vol. 36, no. 8, pp. 1057-1063, 1999.

[20] Y. Zhao, Z. Wan, Z. Feng, D. Yang, Y. Zhang, and F. Qu, “Triaxial compression system for rock testing under high temperature and high pressure," International Journal of Rock Mechanics and Mining Sciences, vol. 52, pp. 132-138, 2012.

[21] M. C. He, J. L. Miao, and J. L. Feng, "Rock burst process of limestone and its acoustic emission characteristics under truetriaxial unloading conditions," International Journal of Rock Mechanics and Mining Sciences, vol. 47, no. 2, pp. 286-298, 2010.

[22] H. Manchao, X. Jia, M. Coli, E. Livi, and L. Sousa, "Experimental study of rockbursts in underground quarrying of Carrara marble," International Journal of Rock Mechanics and Mining Sciences, vol. 52, pp. 1-8, 2012.

[23] M. He, D. Liu, W. L. Gong et al., "Development of a testing system for impact rock burst," Chinese Journal of Rock Mechanics and Engineering, vol. 33, no. 9, pp. 1729-1739, 2014 (Chinese).

[24] Y.-J. Zuo, X.-B. Li, Z.-L. Zhou, C.-D. Ma, Y.-P. Zhang, and W.$\mathrm{H}$. Wang, "Damage and failure rule of rock undergoing uniaxial compressive load and dynamic load," Journal of Central South University of Technology (English Edition), vol. 12, no. 6, pp. 742$748,2005$.

[25] J. Vacek and J. Chocholoušová, "Rock burst mechanics: insight from physical and mathematical modelling," Acta Polytechnica Scandinavica, vol. 48, no. 6, pp. 38-44, 2008.

[26] H. Zhou, R. C. Xu, J. J. Lu, C. Q. Zhang, F. Z. Meng, and Z. Shen, "Study on mechanisms and physical simulation experiment of slab buckling rockburst in deep tunnel," Chinese Journal of Rock Mechanics and Engineering, vol. 34, supplement 2, pp. 36583666, 2015.

[27] A.-H. Lu, X.-B. Mao, and H.-S. Liu, "Physical simulation of rock burst induced by stress waves," Journal of China University of Mining and Technology, vol. 18, no. 3, pp. 401-405, 2008.

[28] T. B. Li, X. F. Wang, and L. B. Meng, "Physical simulation study of similar materials for rock burst," Chinese Journal of Rock Mechanics and Engineering, vol. 30, no. 1, pp. 2610-2616, 2011 (Chinese).

[29] L. W. Chen and S. W. Bai, "Research on plane strain model test of rockburst of circular cavern in hard brittle rockmass," Chinese Journal of Rock Mechanics and Engineering, vol. 26, no. 12, pp. 2504-2509, 2007.

[30] M. C. Liao, Z. K. Guo, F. Liu, and W. X. Cheng, "Determination of the specimen size for model experiment on zonal fracturing of deep rock mass," Journal of Disaster Prevention and Mitigation Engineering, vol. 26, no. 1, pp. 58-62, 2006 (Chinese).

[31] M.-Y. Wang, Z.-P. Zhou, and Q.-H. Qian, “Tectonic, deformation and failure problems of deep rock mass," Chinese Journal of Rock Mechanics and Engineering, vol. 25, no. 3, pp. 448-455, 2006 (Chinese).

[32] J. Haiming, F. Pengxian, W. Mingyang, and F. Xiang, "Elastic adaptive boundary for geomechanical model test," Electronic Journal of Geotechnical Engineering, vol. 19, pp. 2349-2357, 2014.

[33] “The National Standards Compilation Group of People's Republic of China," Tech. Rep. GB/T1972-2005, Standards Press of China, Beijing, China, 2005 (Chinese).

[34] L. Li, M. Y. Wang, P. X. Fan, Y. H. Cheng, Z. Z. Li, and H. M. Jiang, "Development of a deep underground engineering model experiment for loading and unloading test apparatus," Rock and Soil Mechanics, vol. 37, no. 1, pp. 297-304, 2016 (Chinese).

[35] Q.-H. Qian, "Definition, mechanism, classification and quantitative forecast model for rockburst and pressure bump," Rock and Soil Mechanics, vol. 35, no. 1, pp. 1-6, 2014 (Chinese).

[36] P. Fan, H. Xing, L. Ma et al., "Bulk density adjustment of resin-based equivalent material for geomechanical model test," Advances in Materials Science and Engineering, vol. 2015, Article ID 363869, 8 pages, 2015.

[37] X. G. Zhu, "Application of small-angle method in deformation monitoring and research," Surveying and Mapping of Geology and Mineral Resources, vol. 27, no. 4, pp. 38-39, 2011.

[38] M. A. Addis, N. Barton, S. C. Bandis, and J. P. Henry, "Laboratory studies on the stability of vertical and deviated boreholes," in Proceedings of the 65th Annual Technical Conference and Exhibition of the Society of Petroleum Engineers, New Orleans, La, USA, September 1990. 

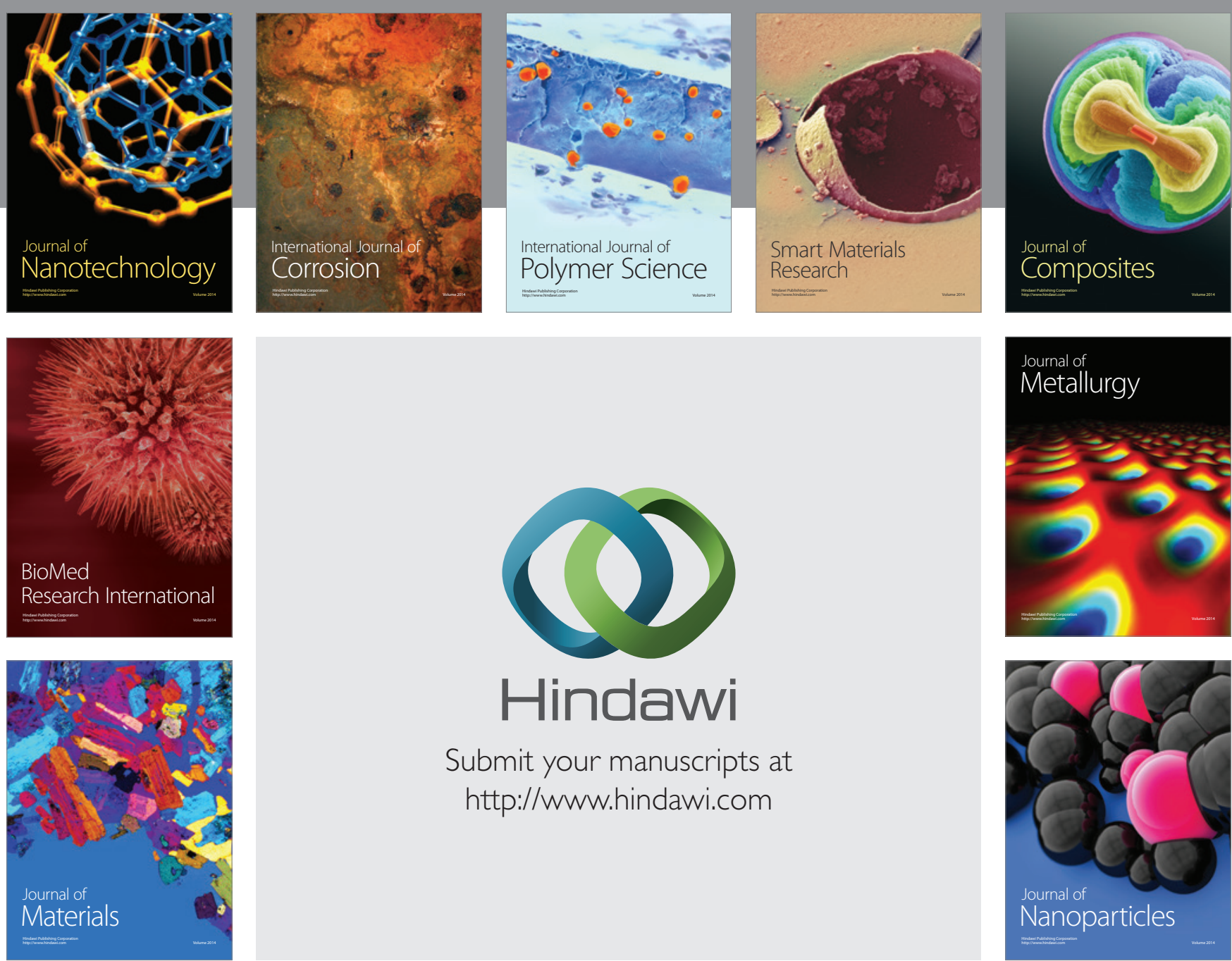

\section{Hindawi}

Submit your manuscripts at

http://www.hindawi.com

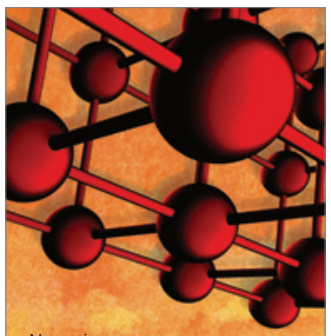

Materials Science and Engineering
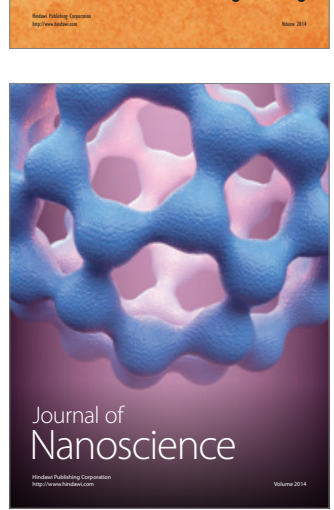
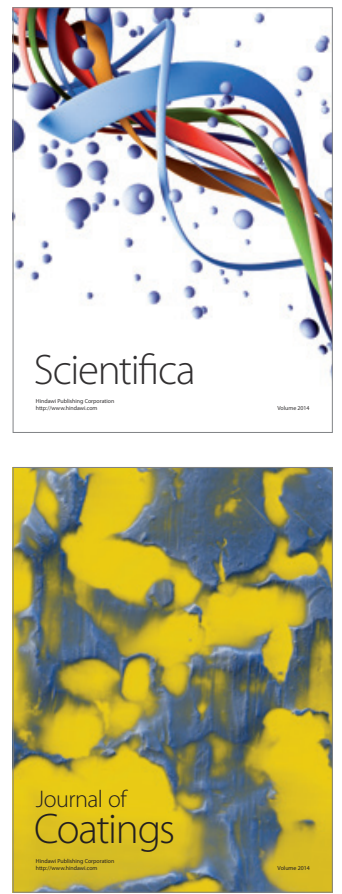
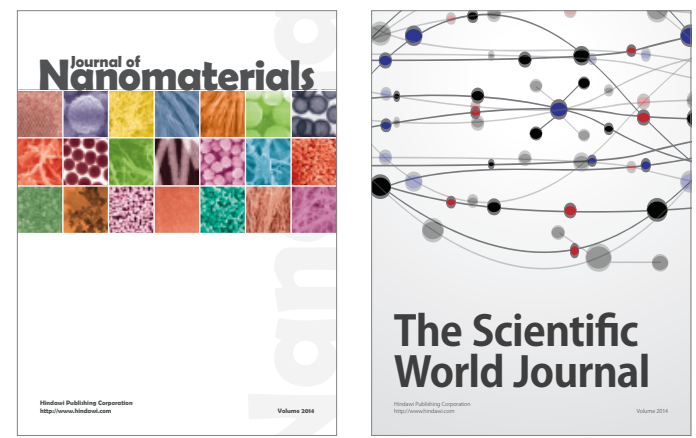

The Scientific World Journal
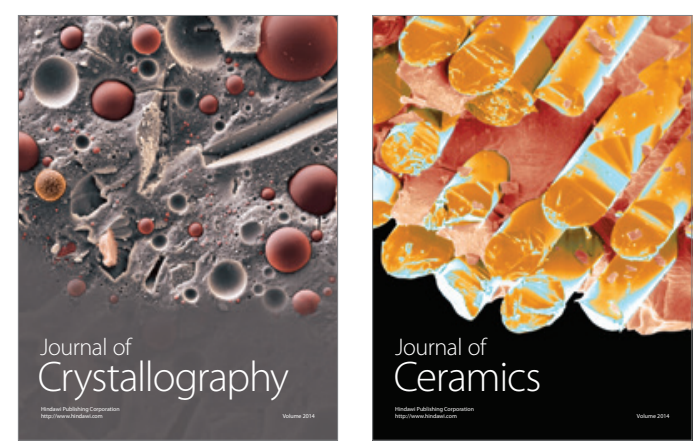
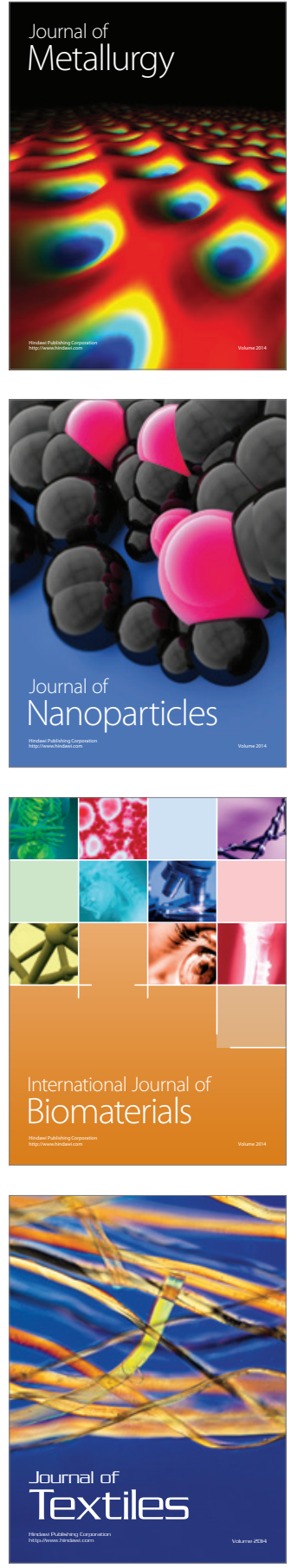